\title{
BMJ Open Fabry disease due to D313Y and novel GLA mutations
}

\author{
Konstantinos Koulousios, ${ }^{1}$ Konstantinos Stylianou, ${ }^{2}$ Panagiotis Pateinakis, ${ }^{3}$ \\ Maria Zamanakou, ${ }^{4}$ Gedeon Loules, ${ }^{4}$ Eleni Manou, ${ }^{3}$ Parthena Kyriklidou, ${ }^{3}$ \\ Christos Katsinas, ${ }^{5}$ Alexandra Ouzouni, ${ }^{6}$ John Kyriazis, ${ }^{7}$ Matthaios Speletas, ${ }^{1}$ \\ Anastasios E Germenis ${ }^{1}$
}

To cite: Koulousios K, Stylianou K, Pateinakis P, et al. Fabry disease due to D313Y and novel GLA mutations. BMJ Open 2017;7:e017098. doi:10.1136/ bmjopen-2017-017098

- Prepublication history and additional material for this paper are available online. To view these files please visit the journal online (http://dx.doi. org/10.1136/bmjopen-2017017098).

Received 23 April 2017 Revised 14 June 2017 Accepted 19 July 2017

\section{(a) CrossMark}

${ }^{1}$ Department of Immunology \& Histocompatibility, School of Medicine, University of Thessaly, Larissa, Greece

${ }^{2}$ University Hospital of Heraklion, Heraklion, Greece

${ }^{3}$ Papageorgiou General Hospital, Thessaloniki, Greece

${ }^{4}$ CeMIA SA, Larissa, Greece

${ }^{5}$ Mpodosakeio General Hospital, Ptolemaida, Greece

${ }^{6}$ Kavala General Hospital,

Kavala, Greece

${ }^{7}$ Chios General Hospital, Chios, Greece

Correspondence to Konstantinos Koulousios; konkoul@gmail.com

\section{ABSTRACT}

Objectives Our aim is to report four novel $\alpha$-gal A gene (GLA) mutations resulting in Fabry disease (FD) and provide evidence of pathogenicity of the D313Y mutation regarding which contradictory data have been presented in the literature.

Setting and participants Twenty-five family members of nine unrelated patients with definite FD diagnosis, 10 clinically suspected cases and 18 members of their families were included in this polycentric cohort study. Primary and secondary outcome measures Genotyping and measurement of lyso- $\mathrm{Gb}_{3}$ was performed in all individuals. The $\alpha$-Gal A activity was measured in all men as well as plasma and urine $\mathrm{Gb}_{3}$ concentration in selected cases. Optical and electron microscopy was performed in kidney biopsies of selected patients. All the above were evaluated in parallel with the clinical data of the patients. Results Fourteen new cases of FD were recognised, four of which were carrying already described GLA mutations. Four novel GLA mutations, namely c.835C $>\mathrm{T}, \mathrm{c} .280 \mathrm{~T}>\mathrm{A}$, c.924A $>C$ and c.511G $>A$, resulting in a classic FD phenotype were identified. Moreover, FD was definitely diagnosed in five patients carrying the D313Y mutation. Eight D313Y carriers were presenting signs of FD despite not fulfilling the criteria of the disease, two had no FD signs and two others were apparently healthy. Conclusions Four novel GLA pathogenic mutations are reported and evidence of pathogenicity of the D313Y mutation is provided. It seems that the D313Y mutation is related to a later-onset milder phenotype than the typical phenotype with normal lysoGb ${ }_{3}$ concentration. Our study underlines the significance of family member genotyping and newborn screening to avoid misdiagnoses and crucial delays in diagnosis and treatment of the disease.

\section{INTRODUCTION}

FD or Anderson-Fabry disease is an X-linked inherited metabolic disorder that results from mutations in the $\alpha$-gal A gene (GLA gene), leading to reduction of the enzyme activity and subsequent accumulation of $\mathrm{Gb}_{3}$ (or GL-3) in plasma, urine and cellular lysosomes throughout the body. These depositions cause a multisystemic pathology with life-threatening manifestations, including renal failure, cardiac and cerebrovascular disease. ${ }^{12}$

\section{Strengths and limitations of this study}

This is the largest series in the literature of clinically evaluated male and female carriers of the $\alpha$-gal A gene (GLA) D313Y mutation supporting its possible pathogenicity that occasionally has been proved by renal biopsy.

- Novel GLA mutations resulting in a classic Fabry disease phenotype are presented.

- The main limitation is the lack of detailed clinical data in older participants.

- Biopsies of affected organs, the gold standard of definite diagnosis, are not available in all cases.

More than 900 currently known GLA mutations have been identified ${ }^{34}$ as causing a variety of clinical manifestations. Most of them are unique to a family (private) and therefore genotype-phenotype correlation is limited. ${ }^{5}$ Diagnosing FD is challenging due to the range of disorders that mimic the disease and the great variety of atypical clinical presentations. As a result, underdiagnosis and misdiagnosis of FD lead to late diagnosis, delays in appropriate treatment and a subsequent negative prognosis. ${ }^{6}$ Human genetic analysis must be performed to exclude or verify a GLA mutation. ${ }^{7}$ Once a diagnosis has been made, biochemical and molecular genetic analysis, as well as genetic counselling, should be made available to all family members. ${ }^{8}$ A detailed pedigree analysis for each patient presenting with FD is crucial, ${ }^{9}$ as it can inform the diagnosis of the proband and the identification of all at-risk relatives. ${ }^{10}$

Our aim is to report four novel GLA mutations resulting in FD and provide evidence of pathogenicity of the D313Y mutation regarding which contradictory data have been presented in the literature.

\section{METHODS}

Study design and setting

This is a polycentric population screening study of individuals from Greece either 
demonstrating phenotypic traits suggestive of FD or belonging to families of patients with a definite FD diagnosis and fulfilling any one of the following inclusion criteria:

- Definite diagnosis of FD.

- Nephrological, cardiac or neurological symptoms suspicious of FD.

- Relatives of patients with definite FD diagnosis.

A cohort of 62 subjects from 19 unrelated families were involved in the study. Twenty-five were relatives of 9 patients with definite FD diagnosis and 18 were relatives of 10 individuals recruited as carriers of FD traits in whom a GLA mutation was detected. The presence of the D313Y mutation in a Greek population was examined by genotyping of 145 apparently healthy subjects (70 men, 75 women). Written informed consent was obtained from each subject or an accompanying relative if legally appropriate. The study was approved by the institutional review board of the University of Thessaly, Larissa.

\section{Clinical assessment}

Patients' medical records were evaluated and a detailed medical history of the family members was obtained, especially regarding heart or kidney disease, cerebrovascular events, death at young age and respective causes of death. All study participants underwent a physical examination particularly focused on cardiac, renal and neurological signs and symptoms. A detailed pedigree was constructed for every family and newborn screening was performed.

\section{Laboratory evaluation}

In DBS, we measured $\alpha$-Gal A activity in all male subjects using tandem mass spectrometry, ${ }^{11}$ lyso-Gb $_{3}$ in all subjects using high-performance liquid chromatography and tandem spectrometry, ${ }^{12}$ as well as plasma and urine $\mathrm{Gb}_{3}$ concentration in selected cases using tandem mass spectrometry. ${ }^{13}$

Optical and electron microscopy was occasionally performed for the study of kidney biopsies.

\section{Genotyping}

Genomic DNA was extracted from peripheral blood using the iPrep Pure Link DNA blood kit (Invitrogen, Thermofisher, USA) according to the manufacturer's instructions. All coding regions and exon-intron splice junctions of the GLA gene were analysed in a targeted custom next-generation sequencing (NGS) platform (Ampliseq custom panel, Thermo Scientific). Analysis of primary data was conducted with Ion Reporter software v.5.2 (Thermo Scientific). Common polymorphisms (UCSC Common SNPs) were excluded and pathogenicity of variations was predicted by bioinformatic analysis using PhyloP, SIFT, Grantham and PolyPhen tools, in comparison to their global (1000 Genomes Global Minor Allele Frequency, ExAC) and European frequency (5000 Exomes European Minor Allele Frequency). The characterisation of variants was based on the recommendations of the American College of Medical Genetics and
Genomics (ACMG) and the Association for Molecular Pathology. ${ }^{14}$

Novel variants were verified by PCR in combination with Sanger sequencing. Amplification of GLA exons (including exon-intron boundaries) was performed in five reactions corresponding to exons $1,2,3,4$, and 5-7, using the primers included in the supplementary material. A total of $100-200 \mathrm{ng}$ of genomic DNA was amplified by PCR in a $30 \mu \mathrm{L}$ reaction mixture using $200 \mu \mathrm{M}$ of each deoxynucleoside triphosphate, $30 \mathrm{pmol}$ of each primer, $1.5 \mathrm{mM} \mathrm{MgCl}_{2}$ and $1.0 \mathrm{U}$ Taq polymerase (Invitrogen, Thermofisher, USA) in a 10x buffer supplied by the manufacturer. Reaction conditions were as follows: for exons 1-3: $94^{\circ} \mathrm{C}$ for $2 \mathrm{~min}$, followed by 30 cycles of $30 \mathrm{~s}$ at $94^{\circ} \mathrm{C}, 30 \mathrm{~s}$ at $58^{\circ} \mathrm{C}, 30 \mathrm{~s}$ at $72^{\circ} \mathrm{C}$, and a final extension at $72^{\circ} \mathrm{C}$ for $5 \mathrm{~min}$. For exons 4 and $5-7$ : $94^{\circ} \mathrm{C}$ for $2 \mathrm{~min}$, followed by 32 cycles of $30 \mathrm{~s}$ at $94^{\circ} \mathrm{C}, 30 \mathrm{~s}$ at $54^{\circ} \mathrm{C}, 30 \mathrm{~s}$ for exon 4 or $75 \mathrm{~s}$ for exons $5-7$ at $72^{\circ} \mathrm{C}$, and a final extension at $72^{\circ} \mathrm{C}$ for $5 \mathrm{~min}$. All PCR reactions were carried out in the Veriti 96-Well Thermal Cycler (Applied Biosystems, Thermofisher, USA). PCR engine apparatus and the emerging PCR products were purified using the PureLink PCR Purification Kit system (ThermoFisher Scientific, USA). Sequencing was performed using the primers described in the supplementary table, using a 3730 DNA Analyzer (Applied Biosystems, Thermofisher, USA) and BigDye Terminator DNA sequencing kit (Applied Biosystems, Thermofisher, USA), according to manufacturer's instructions.

\section{RESULTS}

Nine (all with definite FD) out of the 62 genotyped subjects were carrying five previously described $G L A$ mutations: c.334C $>$ T (p.Arg112Cys, R112C), c.644A $>\mathrm{G}$ (p.Asn215Ser, N215S), c.1153A $>$ C (p.Thr385Pro, T385P), c.453C $>\mathrm{G}$ (p.Tyr151Ter, Y151X) and c.782G $>\mathrm{T}$ (p.Gly261Val, G261V).

The c.937G >T (p.Asp313Tyr，D313Y，NM_000169.2) mutation was revealed in 17 individuals $(54 \pm 14$, range 27-78 years), 7 men (61 \pm 11 , range $45-78$ years) and 10 women ( $49 \pm 15$, range $27-70$ years) but in none of the healthy subjects. Patients' clinical and laboratory findings are presented in table 1 . All male patients $(61 \pm 11$, range $45-78$ years) presented with an $\alpha$-gal A activity decreased in a range of $56.2-87.5 \%$ compared with normal, with the exception of one patient in whom $\alpha$-gal A activity was within the normal range. $\mathrm{LysoGb}_{3}$ concentration was found normal (range $0.8-1.7 \mathrm{ng} / \mathrm{mL}$ ) in all patients, while plasma and urine $\mathrm{Gb}_{3}$ concentration varied, as shown in table 1.

The diagnosis of FD was definitely posed according to the recently published criteria of the disease ${ }^{15}$ in five carriers of this mutation (54 \pm 9 , range 45-65 years). The first (patient no. 1, table 1), a 52-year-old man, was initially diagnosed at the age of 48 with chronic kidney disease (CKD) stage III and was not presenting cardiac or other FD signs. Kidney biopsy performed because of 
Table 1 Characteristics of patients carrying the D313Y mutation. Plasma and urine Gb3 concentration was measured only in patients 1,4 and 5

\begin{tabular}{|c|c|c|}
\hline $\begin{array}{l}\text { Patient/gender/age } \\
\text { (years) }\end{array}$ & FD-related clinical findings & Previous diagnosis \\
\hline $1 / \mathrm{M} / 52$ & $\begin{array}{l}\text { End-stage renal disease - dialysis, acroparesthesias, renal cysts, elevated } \\
\text { plasma and urine } \mathrm{Gb}_{3} \text { concentration }\end{array}$ & FSGS nephropathy \\
\hline $2 / F / 30$ & Healthy & No \\
\hline 3/F/70 & Healthy & No \\
\hline $4 / F / 46$ & $\begin{array}{l}\text { Three strokes of unknown origin, WML on brain MRI, micro-albuminuria, } \\
\text { oedema, acroparesthesias, elevated urine } \mathrm{Gb}_{3} \text { concentration }\end{array}$ & No \\
\hline $5 / F / 65$ & Multiple WML on brain MRI, depression, elevated plasma $\mathrm{Gb}_{3}$ concentration & $\begin{array}{l}\text { MS, RA, spastic } \\
\text { quadriplegia }\end{array}$ \\
\hline $6 / F / 62$ & Acroparesthesias, Gl symptoms since adolescence & No \\
\hline $7 / \mathrm{M} / 45$ & $\begin{array}{l}\text { End-stage renal disease on dialysis, WML and vertebrobasilar vessel changes on } \\
\text { brain MRI, increased cardiac interventricular septum echogenicity, hearing loss } \\
\text { of higher frequencies }\end{array}$ & $\begin{array}{l}\text { Nephropathy of } \\
\text { unknown origin }\end{array}$ \\
\hline $8 / \mathrm{M} / 62$ & End-stage renal disease on dialysis & No \\
\hline 9/F/36 & WML on brain MRI, acroparesthesias & MS \\
\hline 10/M/78 & End-stage renal disease on dialysis & $\mathrm{RA}$ \\
\hline $11 / F / 47$ & LVH, CKD & No \\
\hline 12/M/68 & No FD signs & Myopathy \\
\hline $13 / F / 46$ & No FD signs & NMO \\
\hline $14 / F / 27$ & WML on brain MRI & MS \\
\hline $15 / M / 61$ & End-stage renal disease on dialysis & Diabetic nephropathy \\
\hline 16/M/63 & CKD, hearing loss, multiple ischaemic infarcts on brain MRI & no \\
\hline 17/F/59 & $\begin{array}{l}\text { Cornea verticillata, hearing loss, LVH, acroparesthesias, GI symptoms (pain - } \\
\text { diarrhoea) since adolescence, hypohidrosis, T2-WML or ischaemic infarcts on } \\
\text { brain MRI }\end{array}$ & no \\
\hline
\end{tabular}

non-nephrotic proteinuria, microscopic haematuria and raised serum creatinine, revealed focal and segmental glomerulosclerosis (FSGS) - collapsing variant. At that time, enzyme activity and plasma lyso- $\mathrm{Gb}_{3}$ concentration were normal. Three years after the initial presentation the patient had end-stage renal disease and extreme acroparesthesias. Evaluation of the kidney biopsy using a higher magnification uncovered focal cytoplasmic microvacuolisation of enlarged podocytes (figure 1), with $\alpha$-gal A activity decreased by $50 \%$ and increased plasma $(7.52 \mathrm{nmol} / \mathrm{mL}$, reference: $0.8-4.52)$ and urine $\mathrm{Gb}_{3}$ concentration $(147.49 \mathrm{nmol} / \mathrm{g}$, reference: $<29.00)$. The patient commenced dialysis and enzyme replacement therapy (ERT) with rapid clinical improvement.

A second carrier of the D313Y mutation was a 46-year-old woman (patient no. 4, table 1) who had had a transient ischaemic attack and two ischaemic strokes that had been considered of unknown origin. On evaluation, 1 year after the last stroke, the patient appeared with microalbuminuria, oedema and acroparesthesias on both hands. The microalbuminuria was duplicated after 3 months and acroparesthesias worsened. $\mathrm{Gb}_{3}$ concentration was pathological in urine $(54.08 \mathrm{nmol} / \mathrm{g})$ but normal in plasma. $\mathrm{LysoGb}_{3}$ concentration was normal at that time and remained stable for one more year.
The mother of the above patient (patient no. 5, table 1), 65 years old, had been diagnosed at the age of 50 with multiple sclerosis and was receiving relative medication, without clinical benefit. She was also receiving treatment for pain in the extremities that was attributed to rheumatoid arthritis. During recent years the patient had mobility impairment (reported as spastic quadriplegia after a neurological examination), depression and dementia. Evaluation of the patient revealed pathological plasma $\mathrm{Gb}_{3}$ concentration $(4.7 \mathrm{nmol} / \mathrm{mL})$, white matter lesion (WML) on brain MRI and normal kidney function. LysoGb ${ }_{3}$ concentration was normal and remained so during a 6-month follow-up.

Another carrier of the D313Y mutation was a 45-year-old man (patient no. 7, table 1) on dialysis due to CKD by the age of 25. No kidney biopsy was performed at that time. He reported episodes of haematuria during childhood and adolescence, attributed at that time to vesicoureteral reflux. Enzyme activity was slightly decreased (2.4 $\mu \mathrm{mol} / \mathrm{L} /$ hour, reference: $\geq 2.6)$ and plasma lyso-Gb concentration was normal. Brain MRI revealed WML and vertebrobasilar vessel changes. Moreover, the patient had increased echogenicity of the cardiac interventricular septum on the echocardiogram and sensorineural hearing loss of higher frequencies. The patient commenced ERT. 

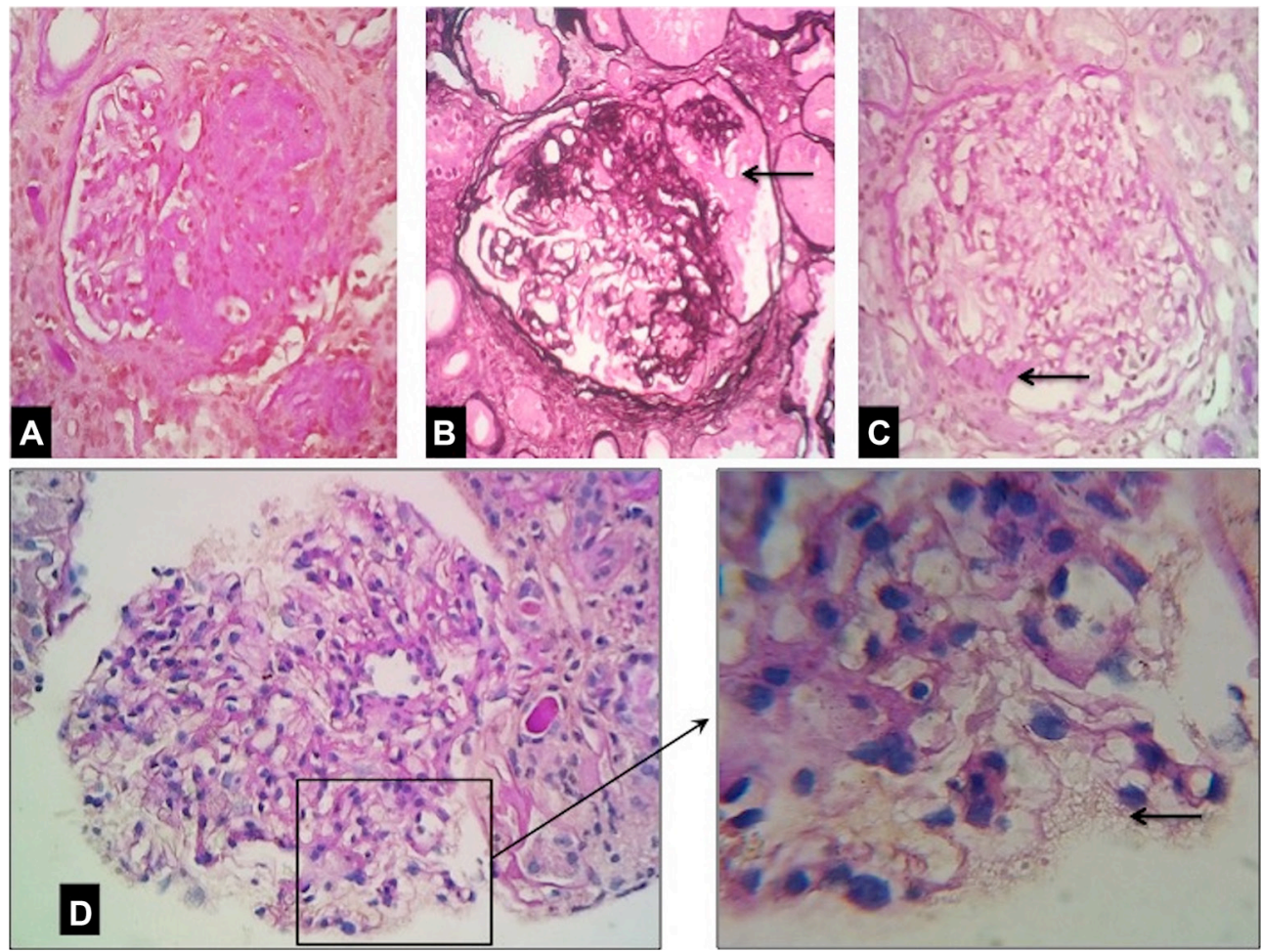

Figure 1 Optical microscopy findings of renal biopsy from a male patient with Fabry disease (FD) carrying the D313Y mutation of the GLA. (A) Glomerulus with segmental sclerosis - PAS $\times 400$. (B) Segmental sclerosis with features of the 'collapsing' variant (arrow) - Jones' silver $\times 400$. (C) Pale appearing glomerulus with a small area of sclerosis adhering to Bowman's capsule (arrow) - PAS $\times 400$. (D) Cytoplasmic microvacuolisation of podocytes (arrow), suggestive of FD - PAS $\times 400$.

The last patient with the D313Y mutation definitely diagnosed with FD was a 60-year-old woman (patient no. 17, table 1) who presented with cornea verticillata corneopathy, WML and ischaemic infarcts on brain MRI despite no stroke being reported, acroparesthesias and gastrointestinal (GI) symptoms (pain, diarrhoea) since adolescence, hypohidrosis, hearing loss and left ventricular hypertrophy (LVH).

Among the remaining 12 D313Y mutation carriers there were two patients with no FD signs and eight patients ( $55 \pm 17$, range $27-78$ years) presenting with other FD signs, mainly neurological; however, they cannot document a definite diagnosis of FD. Especially patient no. 6, table 1 (62-year-old woman) had acroparesthesias and GI symptoms since adolescence and presented with lysoGb $_{3}$ at $1.7 \mathrm{ng} / \mathrm{mL}$ (reference: $\geq 1.8$ ). Accordingly, patient no. 16, table 1 (64-year-old man) presented with CKD, diabetes mellitus and hearing loss, while brain MRI showed multiple ischaemic infarcts despite no stroke being reported. The remaining two D313Y mutation carriers were apparently healthy.

Novel GLA mutations (4) (figure 2) were detected in 13 members $(39 \pm 18$, range $1-69$ years) of four unrelated families (table 2), all fulfilling the diagnostic criteria of a definite diagnosis of FD [15]. The c.835C $>$ T mutation (p.Gln279Ter, Q279X) in exon 6 of the GLA gene was identified in four members (30 \pm 24 , range $1-60$ years) of a Greek family. The proband, a 31-year-old man, presented at the age of 23 with proteinuria (3.5 g/24hours), microscopic haematuria, slightly deteriorated kidney function, right bundle brunch block, mild hypertension and angiokeratomas in the arms and the loin area. He reported pain in the extremities, especially during infections, and inability to sweat. The $\alpha$-gal A activity was close to zero. Cardiac MRI showed moderate LVH. The kidney biopsy showed cytoplasmic vacuolization and extended lysosomal accumulations in all types of kidney cells, especially in the podocytes (figure 3). The patient is currently under ERT with beneficial results in regard with kidney function, proteinuria and pain. Three other members of the family were revealed having with the same mutation and all presented clinical signs of FD. The proband's mother (60 years old) reported a possible TIA at the age of 32. Kidney examination showed albuminuria ( $>500 \mathrm{mg} / 24$ hours), microscopic haematuria and normal kidney function. Cardiac MRI revealed severe LVH (cardiac interventricular septum over $19 \mathrm{~mm}$ ) and on skin examination she showed angiokeratomas in the arms. Her mother (the proband's grandmother) had died at the age of 62, due to cardiac arrest. She had severe LVH and acroparesthesias, which at that time were attributed to Raynaud's phenomenon. The proband's sister (27 years old) had elevated lyso- $\mathrm{Gb}_{3}$ concentration $(2.7 \mathrm{ng} /$ $\mathrm{mL}$ ) and screening of her newborn daughter revealed the mutation too.

Four patients (46 \pm 11 , range $30-56$ years) belonging to another Greek family were carrying the c.280T $>\mathrm{A}$ (p.Cys94Ser, C94S) mutation. The proband, a 48-year-old 




Figure 2 Sanger confirmation of novel mutations.

woman, was diagnosed with FD a year before after presenting with increased lyso-Gb ${ }_{3}$ concentration $(5.4 \mathrm{ng} /$ $\mathrm{mL}$ ), increased plasma $\mathrm{Gb}_{3}$ concentration $(6.14 \mathrm{nmol} /$ $\mathrm{mL}$ ), microalbuminuria of no other origin, cornea verticillata corneopathy, acroparesthesias in both hands and dyshidrosis. Clinical and laboratory data of the other affected members of the family are presented in table 2.

The c.924A>C mutation (K308N - p.Lys308Asn) in exon 6 of the GLA gene was identified in three members of a Greek family (44 \pm 26 , range 17-69 years). The proband, a 46-year-old man, presented at the age of
34 with albuminuria $(0.5-0.6 \mathrm{~g} / 24$ hours $)$, had microscopic haematuria for 10 years and slight hypertension. The kidney function was normal. Kidney biopsy showed slight mesangial proliferative damage and cytoplasmic microvacuolisation of podocytes. The $\alpha$-gal A activity was almost zero. After a 10-year follow-up he had $\mathrm{LVH}$ and proteinuria $(1.8 \mathrm{~g} / 24$ hours $)$. The patient is currently under ERT. His mother and daughter carry the same mutation. The probands grandmother had died at the age of 68 , with severe $\mathrm{LVH}$ and end-stage heart failure.

Table 2 Clinical characteristics of patients with the four novel mutations





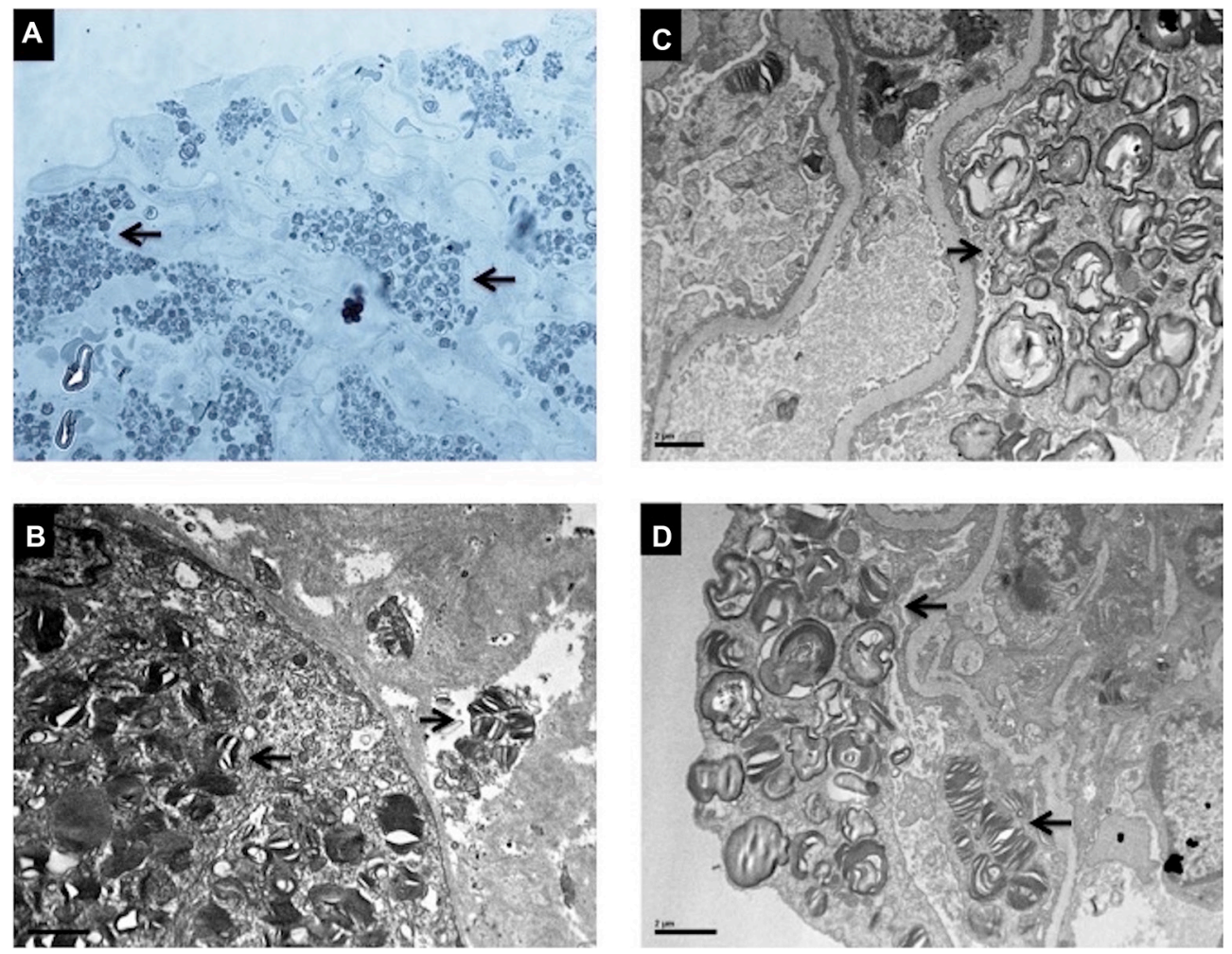

Figure 3 Electron microscopy findings of renal biopsy from a male patient with Fabry disease (FD) carrying the Q279X mutation. Multi-lamellated myelin figures ('zebra' bodies), a typical finding of FD, are marked with black arrows in (A) methylene blue semithin section, (B) tubular cells and a fibroblast and (C,D) podocytes.

Lastly, the c.511G>A mutation (G171S - p.Gly171Ser) in exon 3 of the GLA gene was identified in two members (37 \pm 4 , range $34-39$ years) of an Albanian family living in Greece. The proband, a 39-year-old man, was diagnosed at the age of 32 with severely deteriorated kidney function and proteinuria. No biopsy was performed at that time due to the small size of the kidneys. After nearly a year he presented with severe clinical and laboratory findings of acute renal failure and needed dialysis. Normal kidney function was never restored. FD was definitely diagnosed at the age of 37, as the $\alpha$-gal A activity was extremely low and lyso- $\mathrm{Gb}_{3}$ concentration was $11.9 \mathrm{ng} / \mathrm{mL}$. The patient had LVH, increased pulmonary artery diameter, dilatation of the ascending aorta and aortic valve stenosis, due to which he underwent a valve replacement surgery. Ophthalmological evaluation indicated lipid deposition with blurriness of the cornea. The patient is currently under ERT. His 34-year-old brother was identified with the same mutation and has extremely low $\alpha$-gal A activity, lyso-Gb3 concentration $12,9 \mathrm{ng} / \mathrm{mL}$ and albuminuria of no other aetiology.

\section{DISCUSSION}

\section{The D313Y mutation}

Contradicting results about the pathogenicity of this mutation have been reported in the literature since its first description in $1993 .{ }^{16}$ The mutation has been detected in many series of patients presenting signs of FD. ${ }^{17-24}$ However, Niemann $e t a l^{25}$ describes this variant as non-pathogenic, although his two patients were presenting with decreased $\alpha$-gal A activity. Similarly, Oder et $a l^{26}$ support that the D313Y genotype does not lead to severe organ manifestations as seen in genotypes known to be causal for classical FD and Froissart $e t a l^{27}$ characterise the mutation as a 'pseudodeficient allele', implying that it is a sequence variant which encodes an enzyme that is transported to the lysosomes, where it has about $75 \%$ of normal enzymatic activity. The D313Y mutation has also been referred to as polymorphism, ${ }^{19}$ despite the fact that, according to the ExAC and 1000 Genomes databases, its frequency in the World and European population is below $1 \%$. Finally, it must be mentioned that bioinformatics analysis shows that this mutation is predicted as probably damaging (PolyPhen-2) or damaging (SIFT).

In our study, 5 of 17 carriers of the D313Y mutation (54 \pm 9 , range $45-65$ years) proved to have definite FD according to the recently published criteria of the disease. ${ }^{15}$ The presentation of the disease in our patients indicates that the mutation results in a milder phenotype, with later onset of symptoms. This phenotype, also including milder mono- or oligosymptomatic cases, ${ }^{19}$ is characterised as atypical or type $2 .{ }^{28}$ The late onset of clinical symptoms and the milder than the typical FD phenotype in these patients can be partly explained by the high $\alpha$-gal A residual activity, since there is evidence that the mutated $\alpha$-gal A reaches the lysosomes intracellularly. ${ }^{29}$ Actually, in all but one male D313Y carrier of our study, $\alpha$-gal A activity was decreased. Another reason for the 
decreased activity of the D313Y enzyme in plasma could be a functional intolerance to blood plasma neutral $\mathrm{pH}$ conditions. This effect is irreversible and, once in contact with a neutral or basic $\mathrm{pH}$ environment, the D313Y enzyme remains inactive, even if transferred to optimal $\mathrm{pH}^{21} 29$

Interestingly, the vast majority of our patients with D313Y presented with neurological symptoms and signs. Moreover, one of them was misdiagnosed with MS while two carriers of the mutation, in whom a definite FD diagnosis had not been established yet, were diagnosed with MS and treated accordingly. Similarly the detailed study of the renal biopsy in one of our cases underlies the significance of early detection of Fabry-specific findings in cases with FSGS.

\section{Novel mutations}

The pathogenicity of the above-mentioned novel mutations has been undoubtfedly proved as all carriers had definite FD. Of these carriers, the c.835C $>$ T (p.Gln279Ter, Q279X) is a nonsense mutation causing an interruption of the reading frame by a premature stop codon, which results in a truncated protein. A truncated protein and the subsequent loss of its functionality is strong evidence that the mutation is probably pathogenic for FD [14]. No amino acid change at this position has ever been described in the NCBI and Fabry Database (http://fabrydatabase.org/). ${ }^{30}$

As far as the c.280T>A (C94S), c.924A >C (K308N), c.511G $>$ A (G171S) mutations are concerned, bioinformatics analysis supports their disease-causing effect as they are predicted as probably damaging (PolyPhen-2) and/ or damaging (SIFT). Further evidence of their pathogenicity could be the fact that the same aminoacid changes at the corresponding positions but in different nucleotides have already been described as disease causing. ${ }^{31-33}$

\section{CONCLUSIONS}

We report four novel GLA mutations causing FD. Moreover, we offer strong evidence that the D313Y mutation could be pathogenic. It seems that this mutation is related to a later-onset milder phenotype than the typical phenotype with normal lysoGb ${ }_{3}$.

Additionally our study underlines the significance of family member genotyping, newborn screening and genetic counselling in avoiding misdiagnoses and crucial delays in diagnosis and treatment of the disease. Finally, we confirm the fact that heterozygous women may develop mild to severe FD and that the genotype-phenotype correlation does not exist even among members of the same families.

Acknowledgements We appreciate the help and advice from A Andrikos, $S$ Kouzouka, A Triantafillou, D Kaltsidou, A Kaliantzoglou, A Lysitska, K Papadopoulos, K Zoganas, G Tsivgoulis, Z Tegou, A Fountoglou, T Karapanagiotidis, S Patsialas.

Contributors KK: collection, analysis and interpretation of the data, pedigree analysis, literature review, drafting and revision of the manuscript. KS: renal biopsy and analysis on electron microscope. PP: renal biopsy and analysis on optical microscope. MS, MZ and GL: genotyping and bioinformatics analysis. KS, PP, EM, PK, CK, AO, JK: treating physicians of patients. AEG: design and coordination of the study, revision of the manuscript. All authors approved the final version of the manuscript.

Funding The study has been partially supported by a grant from the Research Committee of the University of Thessaly.

Competing interests KK received travel assistance from Shire and Genzyme and speaker's honoraria from Shire. KS received travel assistance and speaker's honoraria from Shire. PP and A0 received travel assistance from Genzyme and Shire. CK received travel assistance from Shire. AEG received research grants from Shire. The authors MZ, GL, MS, EM, PK, JK, report no competing interests.

Ethics approval This report was approved by the institutional review board of the University of Thessaly, Larissa. Written informed consents for participation were obtained from patients.

Provenance and peer review Not commissioned; externally peer reviewed.

Data sharing statement All data supporting our findings are included in the manuscript.

Open Access This is an Open Access article distributed in accordance with the Creative Commons Attribution Non Commercial (CC BY-NC 4.0) license, which permits others to distribute, remix, adapt, build upon this work non-commercially, and license their derivative works on different terms, provided the original work is properly cited and the use is non-commercial. See: http://creativecommons.org/ licenses/by-nc/4.0/

(C) Article author(s) (or their employer(s) unless otherwise stated in the text of the article) 2017. All rights reserved. No commercial use is permitted unless otherwise expressly granted.

\section{REFERENCES}

1. Germain DP. Fabry disease. Orphanet J Rare Dis 2010;5:30.

2. Schiffmann R. Fabry disease. Pharmacol Ther 2009;122:65-77.

3. Abecasis GR, Auton A, Brooks LD, et alAn integrated map of genetic variation from 1,092 human genomes. Nature 2012;491:56-65.

4. The Human Gene Mutation Database at the Institute of Medical Genetics in Cardiff. http://www.hgmd.cf.ac.uk/ (accessed 13 June 2017).

5. Laney DA, Fernhoff PM. Diagnosis of Fabry disease via analysis of family history. J Genet Couns 2008;17:79-83.

6. Mehta A, Ricci R, Widmer U, et al. Fabry disease defined: baseline clinical manifestations of 366 patients in the Fabry Outcome Survey. Eur J Clin Invest 2004;34:236-42.

7. Gal A, Hughes DA, Winchester B. Toward a consensus in the laboratory diagnostics of Fabry disease - recommendations of a European expert group. J Inherit Metab Dis 2011;34:509-14.

8. Winchester B, Young E. Biochemical and genetic diagnosis of Fabry diseaseChapter 18. In: Mehta A, Beck M, Sunder-Plassmann G, eds. Fabry disease: perspectives from 5 years of FOS. Oxford: Oxford PharmaGenesis, 2006.

9. Hughes DA, Evans S, Milligan A, et al; A multidisciplinary approach to the care of patients with Fabry diseaseChapter 35. In: Mehta A, Beck M, Sunder-Plassmann G, eds. Fabry disease: Perspectives from 5 years of FOS. Oxford: Oxford PharmaGenesis, 2006.

10. Laney DA, Fernhoff PM. Diagnosis of Fabry disease via analysis of family history. J Genet Couns 2008;17:79-83.

11. Chamoles NA, Blanco M, Gaggioli D. Fabry disease: enzymatic diagnosis in dried blood spots on filter paper. Clin Chim Acta 2001;308:195-6.

12. Aerts JM, Groener JE, Kuiper S, et al. Elevated globotriaosylsphingosine is a hallmark of Fabry disease. Proc Natl Acad Sci U S A 2008;105:2812-7.

13. Boscaro F, Pieraccini G, la Marca G, et al. Rapid quantitation of globotriaosylceramide in human plasma and urine: a potential application for monitoring enzyme replacement therapy in AndersonFabry disease. Rapid Commun Mass Spectrom 2002;16:1507-14.

14. Richards S, Aziz N, Bale S, et al. Standards and guidelines for the interpretation of sequence variants: a joint consensus recommendation of the American College of Medical Genetics and Genomics and the Association for Molecular Pathology. Genet Med 2015;17:405-23.

15. Biegstraaten M, Arngrímsson R, Barbey F, et al. Recommendations for initiation and cessation of enzyme replacement therapy in patients with Fabry disease: the European Fabry Working Group consensus document. Orphanet J Rare Dis 2015;10:36. 
16. Eng CM, Resnick-Silverman LA, Niehaus DJ, et al. Nature and frequency of mutations in the alpha-galactosidase $\mathrm{A}$ gene that cause Fabry disease. Am J Hum Genet 1993;53:1186-97.

17. Gaspar P, Herrera J, Rodrigues D, et al. Frequency of Fabry disease in male and female haemodialysis patients in Spain. BMC Med Genet 2010;11:19.

18. Wang RY, Bodamer OA, Watson MS, et al. ACMG Work Group on Diagnostic Confirmation of Lysosomal Storage Diseases. Lysosomal storage diseases: diagnostic confirmation and management of presymptomatic individuals. Genet Med 2011;13:457-84.

19. Lukas J, Giese AK, Markoff A, et al. Functional characterisation of alpha-galactosidase a mutations as a basis for a new classification system in fabry disease. PLoS Genet 2013;9:e1003632.

20. Böttcher T, Rolfs A, Tanislav C, et al. Fabry disease - underestimated in the differential diagnosis of multiple sclerosis? PLoS One 2013;8:e71894.

21. Lenders $M$, Duning T, Schelleckes $M$, et al. Multifocal white matter lesions associated with the D313Y mutation of the $\alpha$-galactosidase A gene. PLoS One 2013;8:e55565.

22. Samuelsson K, Kostulas K, Vrethem M, et al. Idiopathic small fiber neuropathy: phenotype, etiologies, and the search for fabry disease. J Clin Neurol 2014;10:108-18.

23. Becker J, Rolfs A, Karabul N, et al. D313Y mutation in the differential diagnosis of white matter lesions: Experiences from a multiple sclerosis outpatient clinic. Mult Scler 2016;22:1502-5.

24. De Brabander I, Yperzeele L, Ceuterick-De Groote C, et al. Phenotypical characterization of $\alpha$-galactosidase A gene mutations identified in a large Fabry disease screening program in stroke in the young. Clin Neurol Neurosurg 2013;115:1088-93.
25. Niemann M, Rolfs A, Giese A, et al. Lyso-Gb3 indicates that the Alpha-Galactosidase A mutation D313Y is not clinically relevant for Fabry Disease. JIMD Rep 2013;7:99-102.

26. Oder D, Üçeyler N, Liu D, et al. Organ manifestations and long-term outcome of Fabry disease in patients with the GLA haplotype D313Y. BMJ Open 2016;6:e010422.

27. Froissart R, Guffon N, Vanier MT, et al. Fabry disease: $\mathrm{D} 313 \mathrm{Y}$ is an alpha-galactosidase $\mathrm{A}$ sequence variant that causes pseudodeficient activity in plasma. Mol Genet Metab 2003;80:307-14.

28. Lenders M, Weidemann F, Kurschat $C$, et al. Alpha-Galactosidase $A$ p.A143T, a non-Fabry disease-causing variant. Orphanet J Rare Dis 2016;11:54.

29. Yasuda M, Shabbeer J, Benson SD, et al. Fabry disease: characterization of alpha-galactosidase $\mathrm{A}$ double mutations and the D313Y plasma enzyme pseudodeficiency allele. Hum Mutat 2003;22:486-92.

30. Meiji Pharmaceutical university. http://fabry-database.org (accessed 15 Feb 2017).

31. Shabbeer J, Yasuda M, Benson SD, et al. Fabry disease: identification of 50 novel alpha-galactosidase A mutations causing the classic phenotype and three-dimensional structural analysis of 29 missense mutations. Hum Genomics 2006;2:297-309.

32. Blaydon D, Hill J, Winchester B. Fabry disease: 20 novel GLA mutations in 35 families. Hum Mutat 2001;18:459.

33. Shimotori M, Maruyama $\mathrm{H}$, Nakamura $\mathrm{G}$, et al. Novel mutations of the GLA gene in Japanese patients with Fabry disease and their functional characterization by active site specific chaperone. Hum Mutat 2008;29:331. 
Correction: Fabry disease due to D313Y and novel

GLA mutations

Koulousios K, Stylianou K, Pateinakis P, et al. Fabry disease due to D313Y and novel GLA mutations. BMJ Open 2017;7:e017098. doi:10.1136/bmjopen-2017-017098.

The footnotes should include the following statement:

Patient consent Written consent to publish these case reports has been obtained from the patient or next of kin.

Open Access This is an Open Access article distributed in accordance with the Creative Commons Attribution Non Commercial (CC BY-NC 4.0) license, which permits others to distribute, remix, adapt, build upon this work non-commercially, and license their derivative works on different terms, provided the original work is properly cited and the use is non-commercial. See: http://creativecommons.org/licenses/by-nc/4.0/

(c) Article author(s) (or their employer(s) unless otherwise stated in the text of the article) 2018. All rights reserved. No commercial use is permitted unless otherwise expressly granted.

BMJ Open 2018;8:e017098corr1. doi:10.1136/bmjopen-2017-017098corr1

Check for updates 